make it so yielding as not to irritate the sensitive and restless parts with which it must come in contact; so that it might at all times be retained in place without inconvenience, while eating, drinking, or during sleep. At the same time, it was required to possess a degree of strength and firmness sufficient to sustain the force of any sudden shock, as in coughing, sneezing, or laughing, without the risk of being displaced, or in any way deranged. Durability of the stbstance composing the velum was also regarded as a point of the first importance to ensure its usefulness. The material made use of, as prepared by $\mathrm{Mr}$. Goodyeare, and managed according to his instructions, was found (after some practice in the manipulation necessary to bring it to the shape required) to resist the combined action of all the decomposing agents to which it must become subjected-viz., motion, animal heat, the moisture and acids of the mouth, and the oils of the food. The means afterwards devised to keep it in order, freeing it from deposits, and thus preventing foetor, consist in the occasional use of some alkaline or aromatic preparation.

We would now willingly add some account of the elocutionary practice and discipline resorted to in order to obtain the full benefit of the instrument after its adaptation; but this may well be deferred to a future paper, more space having already been occupied, than was at first intended-the purpose of this communication is indeed merely to announce what had thus far been accomplished.-London Lancet.

\title{
ON A SOURCE OF ERROR IN SUPPOSED INFANTICIDE.
}

By James A. Sewell, M.D., Quebec.

ThE following case is, I conceive, interesting in a medico-legal point of view, particularly when taken in connection with the coroner's inquest lately held at Islew'orth, Eng., on the body of Ann Pendry's child, the particulars of which are reported and ably commented upon by $\mathrm{Wm}$. Ryan, M.R.C.S.E., in the Lancet for June 21st, 1845. I may merely here mention, for the benefit of those who have not seen the report, that the above-named Ann Pendry was delivered of a child in a privy, that the child was shortly after found dead at the bottom of the privy, and that a verdict of wilful murder was returned by the coroner's jury against the unfortunate mother.

CASE.-Mrs. B., ætat. 30, married, and pregnant with her first child, was seized during the night of the 20th inst. with labor pains. Being a refugee from the late fire, she occupied part of a garret in which two or three other families and some young men were sleeping. Feeling a natural delicacy, at being confined under such circumstances, she suppressed her cries until daylight, when she descended into a lower apartment, in which resided a woman who had been recently confined by me, to whom she detailed her feelings, requesting, at the same time, that some warm water might be given her to "sit over," to relieve what she described as a great pressure at the lower part of the bowels. She had bardly seated herself upon the edge of a rather high chair, when a severe 
bearing-down pain seized her, and before any assistance could be afforded (though one or two women were in the room) the child was forcibly expelled, and fell head-foremost on the floor, being killed upon the spot.

I should have mentioned that $\mathbf{I}$ was sent for immediately after Mrs. B. had descended into the lower chamber, but did not arrive till about twenty minutes after the delivery. The child, which was a remarkably fine one, was perfectly dead, and still attached by the cord to the placenta, which came away shortly after the infant.

In the above case not the slightest suspicion of criminality can attach to the mother; but, suppose the delivery to have taken place under circumstances precisely similar to those in Pendry's case, though there would be ground for a medico-legal investigation, still, with the fact brought before them by the coroner, that cases such as I have now reported do not unfrequently occur, a jury should be extremely cautious how they blast a poor creature's character by returning such a verdict as that recorded against this unfortunate woman.

I am happy to have it in my power, by a recent case in point, to support the view taken by Mr. Ryan._British Amer. Med. Jour.

[In connection with the above interesting case by Dr. Sewell, the two following cases are copied from late Nos. of the London Lancet, the first of which is related by J. B. Prowse, Esq., a surgeon of Clifton; and the other by Dr. A. Blacklock, of Dumfries.]

One positive fact is worth more than all the negative evidence which can be brought forward on any subject, and for this reason the subjoined case is narrated. When a pupil, I was engaged by a poor woman to attend her during her accouchement; she was a native of Ireland, and a remarkably fine and well-formed person. She had already borne two children. On the day of her delivery I was requested to call on her, for she thought her confinement was near at hand. Her attendants said she was in no pain, but that she appeared uneasy. I waited on her, and found her on the bed, smiling, and expressing a hope that she had not summoned me unnecessarily, but that, as she never suffered much in labor, I would excuse her if she was wrong. On examination, I was surprised to find the head of the child in the upper part of the vagina, and was puzzled to account for there having been no pains to lead to the suspicion of the real nature of the case. No sooner was my hand withdrawn, and my back turned to speak to the attendants, than there occurred one single effort of the uterus, and the child was in the world. I never shall forget the circumstance. To say that there was pain, would be wrong. I believe what the woman stated to me as truth at the moment, that "she scarcely experienced any uneasiness." Not to occupy any more space of your most valuable journal, 1 will merely say, in conclusion, that on reading the report of the case at Isleworth, I saw how possible it was that the woman should be innocent.

Now, that facts are so uniformly preferred to theories, permit me to contribute to your useful pages the following case, which occurred to myself so long ago as Feb. 26th, 1823. At about midday I was hur- 
riedly called to the wife of a clergyman, who had been suddenly taken in labor of her second child. She had been sewing, and occasionally reading, in the parlor, for an hour before, but without suffering any pain or uneasiness to lead her to suppose that labor had commenced, or was even threatening, when in an instant she experienced a strong bearingdown pain, which induced her to get upon her legs, and endeavor to walk into an adjoining bed-room. But before she had proceeded more than a few yards, another pain threw the infant upon the carpet. The cord was ruptured close to the umbilicus, but fortunately did not bleed from the foetal portion. The placenta was partially detached, and the most alarming flooding immediately followed. By introducing my hand, irritating the uterus, and carefully extracting the after-birth, administering brandy freely, and applying cold water and well-adjusted pressure to the abdomen, my patient soon rallied, and made a good recovery. I may observe, that the infant was not injured by the fall; indeed, the fall must have been much lessened by the cord.

\section{THE BOSTON MEDICAL AND SURGICAI, JOURNAL.}

B OSTON, A UGUST 27,1845 .

The Butler Hospital for the Insane in Rhode Island.-An apology is due for not having sooner noticed the Report to the Trustees of the proposed Lunatic Hospital in Rhode Island, by Dr. Bell, of the McLean Asylum, whose good judgment and taste are both apparent in the report. This newly projected institution is to be located at Providence. Funds exceeding $\$ 130,000$ were received for the purpose the past year, including a legacy of $\$ 30,000$ from Mr. Brown, and $\$ 40,000$ from Mr. Cyrus Butler. The proposed institution takes its name from the last-mentioned donor. Three miles from the city of Providence, 120 acres of land have been purchased. With a desire of having the very best contrived edifice -one that shall embrace all the advantages known either at home or abroad-Dr. Bell was induced by the Trustees to visit Europe for the exclusive purpose of ascertaining what was best, most convenient and tasteful in this kind of architecture.

"Dr. B. sailed early in January last for London; after examining the various public and private metropolitan asylums, and the larger public ones to the south, he passed over to the Continent-remained a fortnight at Paris and its vicinity, and thence throngh Belgium, intending to visit the institutions on the Rhine. Receiving, however, such information as led him to the opinion that his short stay would not be most profitably expended in that direction, he returned to England and visited a very considerable proportion of the most recent and best asylums in Great Britain. Amongst those, to which, as the most perfect and best designed, he gave the most particular attention, were the Surrey, Nơrthampton, Leicester, Nottinghám, Lincoln, Wakefield, the two at York, Glasgow; Edinburgh and Belfast. Many of the earlier and unimproved asylums were visited during the 